\title{
Proximal spinal muscular atrophy type 2
}

INSERM

\section{Source}

INSERM. (1999). Orphanet: an online rare disease and orphan drug data base. Proximal spinal muscular atrophy type 2. ORPHA:83418

Proximal spinal muscular atrophy type 2 (SMA2) is a chronic infantile form of proximal spinal muscular atrophy (see this term) characterized by muscle weakness and hypotonia resulting from the degeneration and loss of the lower motor neurons in the spinal cord and the brain stem nuclei. 